\title{
Earthquake risk perception in Belgrade: implications for disaster risk management
}

\author{
Jelena Planići, Vladimir M. Cvetković123* \\ 1 Scientific-Professional Society for Disaster Risk Management, Dimitrija Tucovića 121, Belgrade, Serbia \\ 2 Faculty of Security Studies, University of Belgrade, Gospodara Vučića 50, 11040 Belgrade, Serbia; \\ vmc@fb.bg.ac.rs \\ 3 International Institute for Disaster Research, Dimitrija Tucovića 121, Belgrade, Serbia. \\ * Correspondence: vmc@fb.bg.ac.rs.
}

\begin{abstract}
This paper presents quantitative research results regarding the influence of demographic factors on the earthquake risk perception of the citizens of Belgrade. This research aims to determine how much the citizens of Belgrade are aware of the risk and prepared to react in the event of an earthquake. The relationship between gender, age, level of education, and facility ownership with risk perception was examined. T-test, One-way ANOVA, and Pearson correlation coefficient were used to examine the relationship between the variables and the earthquake risk perception. The survey was conducted using a questionnaire that was given and then collected online among 235 Belgrade respondents during September 2020. The questions were divided into three categories. The first part of the questionnaire was consisted of general questions about the demographic characteristics of the respondents, then the questions that would determine the level of awareness of the respondents about earthquakes, and finally, the questions for determining the respondents' preparedness. The results of the research show that women have a higher perception of risk. It has been proven that the youngest respondents from the age category of 18-30 have the lowest risk perception. The influence of education level in no case showed a statistically significant correlation with risk perception.
\end{abstract}

Keywords: disasters, earthquake, risk perception, management, preparedness.

\section{Introduction}

Given the catastrophic consequences of earthquakes, it is necessary to reduce risks: avoid construction in seismically endangered areas, build seismically designed facilities, design and implement an appropriate warning system that would alert residents a few seconds before an earthquake occurs (Cvetković and Filipović, 2019). In addition to the significant development of seismology, it is of great concern that the place and beginning of the earthquake cannot be predicted yet, as well as the consequences it can cause (Cvetković et al., 2014; Cvetković, 2020; Jakovljević, Cvetković and Gačić, 2015). The essential characteristics of earthquakes as natural hazards are (Cvetković, 2020): they usually appear suddenly and without warning; there are scales for measuring earthquake intensity, but earthquakes cannot be predicted; areas prone to earthquakes are zoned; in addition to the intensity of earthquakes, the consequences of earthquakes also depend on the degree of resistance of built structures and other objects in the environment; usually cause significant damage to critical infrastructure; cause other secondary hazards such as tsunamis, nuclear disasters, fires, explosions, and critical infrastructure bursts; the duration of the tremor, local conditions and the degree of resilience affect the severity of the earthquake consequences. 
There are many ways to reduce the risks posed by earthquakes: land use planning to avoid earthquake-prone areas; engineering solutions (e.g., construction of earthquake-resistant buildings; engineering soils for risk reduction); warning systems that give a few seconds of warning before the ground shakes; and earthquake preparedness (Becker, Paton, Johnston, \& Ronan, 2012). The use of an early warning system cannot reduce the danger, but the adverse effects of an earthquake can be reduced. Given that even in high-risk areas, an earthquake warning comes no more than 10 seconds before an earthquake, all activities must be highly automated and reliable. However, even a short warning period represents progress towards more reliable measures and systems (Gasparini, Manfredi, \& Zschau, 2011). It has been shown that states that have implemented strict construction laws have suffered less from the earthquake, with the improvement of existing laws. An example of this can be seen in the aftermath of two similar earthquakes in New Zealand and Haiti, magnitude 7, which resulted in no deaths in New Zealand while there were 300,000 in Haiti (Shapira, Aharonson-Daniel, \& Bar-Dayan, 2018).

The term "seismic risk" means the possibility of consequences after an earthquake of a certain intensity in a particular area. For seismic risk studies, it is crucial to understand risk perception. Two theories explain risk perception: psychometric and socio-cultural theory (Shrestha et al., 2018: 81). The psychometric theory represents a theoretical framework that argues that individuals subjectively define risk and are influenced by various psychological, social, institutional, and cultural factors (Sjöberg, Moen, \& Rundmo, 2004). Scientists who have practiced the psychometric approach have created a methodology for creating quantitative approaches or cognitive maps of risk perceptions. Slovic et al. (1985) analyzed nine risk characteristics: a) whether people consciously agreed to the risk; b) whether the consequences of the risk are seen immediately or later; c) how well the risk is known to those exposed to it; d) how well the risk is known to science; e) how much can be controlled; f) whether the risk is new; e) whether the risk can cause a disaster, killing many people; $h$ ) whether it causes fear in people; h) how terrible consequences it can cause. Together, these characteristics form two factors used to develop cognitive maps: fear and knowledge of risk (Griffiths, 2015). The goal of psychometric research is to find out why some people are more tolerant of dangers than others and why they require more regulations and safety standards for certain dangers (Slovic, 1987). By examining perceptions of different activities, dangers and technologies and using these findings, they predict how much people want to mitigate the consequences of these dangers. The classification of risk characteristics shows why people react strongly to some hazards and require reasonable regulations, while they are entirely uninterested in some hazards (Henrich et al., 2018). The socio-cultural theory was developed by anthropologists and sociologists and is based on the view that risk perception is shaped following the cultural beliefs of a particular group (Shrestha et al., 2018). There are a large number of foreign papers dealing with risk perception, and they are mainly divided into two categories: 1) papers that examine subjectivity in risk attitudes that show that people overestimate risks with low probability and underestimate potential risks; and 2) papers that investigate which different factors affect risk perception and how these factors could be classified (Sund, Svensson, \& Andersson, 2017). Risk perception depends on several factors such as gender, age, education, place of residence, and previous experience with disasters, and by the earthquake is meant the number of earthquakes experienced and losses suffered (Tian et al., 2014). 
Risk perception refers to people's beliefs, attitudes, assessments, and feelings about the likelihood and consequences of events. Citizens perceive risks differently, and the very perception of risk influences decision-making at the individual, organizational and municipal levels (Cvetković, 2017). Scientists believe that risk perception can affect their level of preparedness, response, and disaster recovery (Ho, Shaw, Lin, \& Chiu, 2008; Bronfman et al., 2016; Qing, Guo, Deng, \& Xu, 2021). Without a good understanding of how people perceive risk, risk reduction policies and their implementation can be ineffective. Risk perception surveys provide essential insights into people's willingness to take preventive action and serve as guidelines for creating risk reduction policies (Fernandez, Tun, Okazaki, Zaw, \& Kyaw, 2018). In addition, disaster risk communication affects risk perception and aims to prevent and mitigate disaster damage, prepare the population for disasters, disseminate information during disasters, and assist in later recovery (Bradley, McFarland, \& Clarke, 2016). The way in which the authorities present the risk affects how people will understand and react to the risk of natural disasters (Heilbrun, Wolbransky, Shah, \& Kelly, 2010).

Research shows that people take more preventive measures when they are told that failure to take action will harm them (negative framework) than when they are told that taking action leads to a safe outcome (positive framework) (Henrich, McClur, \& Crozier, 2015). Trust in government and experts is a factor that significantly affects the perception of risk and the preparedness measures that people take before natural disasters occur. It has been shown that people can perceive risk higher than if trust is low (Bronfman, Cisternas, López-Vázquez, \& Cifuentes, 2016). On the other hand, too much trust in the government and its measures can lead to the population not taking any additional measures, even though they are aware of the problems that can lead to natural disasters. In such cases, trust in government is not an advantage in the fight against disasters. The nature of natural hazards is such that it is impossible to prevent their consequences. Therefore, it is crucial to take preventive measures to reduce the impact of natural disasters and their consequences. Citizens living in high-risk areas and those who have suffered severe psychological and material consequences are often more aware of the threats posed by natural disasters. It happens that people who have avoided the harmful consequences of disasters, even though they live in a region that is at high risk, develop the confidence that they can always cope with the dangers without taking measures (Cvetković, 2016).

\subsection{Literary review}

Risk perception is a critical factor in forming behavior patterns in case of risk and is a prerequisite for making decisions regarding adopting preventive measures. In order to develop adequate information and risk communication strategies, it is necessary to know which factors influence risk perception (Plapp \& Werner, 2006). Numerous studies have been conducted to examine which factors influence the perception of disaster risk (Armaş, 2006; Armaş et al., 2017; Shapira et al., 2018; Mızrak, Özdemir, \& Aslan, 2021). For example, a study conducted in Myanmar (Fernandez et al., 2018) showed that females better perceive risk than males. Also, the authors found no connection between previous experience and risk perception, respondents who had encountered an earthquake have less knowledge than those who do not have such experience. However, those with experience expect more significant material consequences. Also, numerous studies have been conducted concerning 
examining previous experience with natural disasters on risk perception (Plapp \& Werner, 2006; Kung \& Chen, 2012; Knuth, Kehl, Hulse, \& Schmidt, 2014; Sun \& Xue, 2020). Shapira et al. (2018) research has shown that previous experience with disasters leads to a better perception of risk and willingness to take preventive measures. The same results were obtained in a study in China (Xu et al., 2020). The research results in Pakistan (Qureshi, Khan, Rana, Ali, \& Rahman, 2021) found that seismic risk perceptions differ significantly with age, income, experience, and type of home in which one lives. People who suffered from earthquakes in the past had a higher perception of risk, while people who built their houses from engineering materials tended to have a lower perception of risk. Examining the risk population's demographic characteristics (gender, age) is vital for any research. Numerous studies have been conducted on the influence of demographic factors on risk perception (Armaş \& Avram, 2008; Jones et al., 2013; Rahman, 2019; Cvetković and Filipović, 2019). The most common results obtained in research on demographic determinants of risk perception are that women perceive risks more than men, while patterns are not observed in other aspects of demographic factors (Sund et al., 2017).

Numerous studies have been conducted concerning the relationship between gender and risk perception (Tian et al., 2014; Fernandez et al., 2018; Buylova et al., 2019). In general, the results showed that women have a higher level of risk perception than men. In addition to biological and physical characteristics, differences in the perception of risk between the sexes are also influenced by social and cultural factors. This conclusion was reached in a study conducted by Tian et al. (2014) in China, Fernandez et al. (2018) in Myanmar, and Bronfman et al. (2016) in Chile. Research in Dhaka (Rahman, 2019) also confirmed that women better perceive risk and are better prepared than male respondents. As many as 63\% of women have a first aid kit, compared to $40 \%$ of male respondents. Men are expected to be involved in the disaster recovery process. We also have an example of an earthquake risk perception survey in Taiwan (Kung \& Chen, 2012) that showed that women are more afraid of earthquakes and the consequences they can suffer, while there were no gender differences in knowledge of mitigation measures. A study conducted in Turkey, where all respondents were female, showed a high perception of risk and fear of earthquakes (Mizrak et al., 2021). The results indicate that it is necessary to pay more attention to women in educational activities because women who are exposed to dangers in everyday life become more vulnerable in disaster situations, and their exposure to disasters increases significantly. Poor women are more at risk of natural disasters (Fothergill, 1996). Women's vulnerability, especially in underdeveloped countries, is attributed to gender inequality, and women tend to perceive the risk as higher if it could harm their families. When a disaster occurs, the mortality rate is higher among women than men in underdeveloped countries due to discrimination and the traditional role of women as someone who takes care of children and family. This was also confirmed in Bangladesh, a country where gender discrimination is tolerated, and data shows that during the disasters in this country, most of the casualties were women (Rahman, 2019). In developed countries, there are indications that higher mortality of women is in natural disasters caused by earthquakes, while men are more likely to die in atmospheric disasters (Fothergill, 1996).

Numerous studies have also been conducted about the influence of age on risk perception (Ainuddin et al., 2014; Shapira et al., 2018; Rego et al., 2018, Cvetković and Filipović, 2019; Qureshi et al., 2021). A survey was conducted in Bangladesh in which citizens older than 15 were surveyed (Rahman, 2019). Thanks to efforts to improve earthquake 
preparedness and knowledge among young people, by introducing lessons on improving earthquake preparedness in primary and secondary schools, respondents aged 15-19 had better knowledge than those aged 20-29. However, it is necessary to work on improving knowledge and preparedness in all age categories. Research conducted in Mexico and Ecuador aimed to determine how residents of cities where natural disasters have occurred perceive risk and their estimates for future events (Jones et al., 2013). The results showed that younger people think that it is very likely to experience a disaster again. Although younger people are not significantly more concerned than older people living in the cities where the disaster occurred, their past experiences have taught younger urban residents that dangerous events are possible. They, therefore, do not rule out the possibility that they may recur. In addition, a study conducted in Bucharest (Armaş, 2006) showed that perceptions of earthquake risk change with age. The most significant percentage of people who admitted to being very afraid of earthquakes were in the age group of over 66, which can be explained by the fact that older people are more vulnerable than younger ones, while those in the age group 15-25 showed disinterest and the lowest risk perception. The same results were obtained in a study in Pakistan (Ainuddin et al., 2014), whose large part of the territory is situated in the seismic belt of the Himalayas. Older people simply need more time to recover from disasters, both physically and financially.

Research in Taiwan has shown that education plays a role in the perception of risk control. People with more years of education had a higher level of control, regardless of the type of disaster. Highly educated people can more easily access and understand new information. As a result, they may feel a greater degree of control over the disaster (Ho et al., 2008). The research on the perception of earthquake risk conducted by Cvetković \& Filipović (2019) in Serbia showed that those with the lowest level of education show a higher probability of earthquakes than those with the highest level of education. It can be explained by the fact that highly educated respondents know that Serbia is not in a region that is prone to frequent and intense earthquakes, and respondents with a lower level of education probably associate their views with earthquakes that occur in the area. The results of a study conducted by Rahman (2019) showed that respondents with lower education are less prepared than highly educated respondents. When it comes to risk perception of high school students, research has been conducted in Serbia (Cvetković \& Stanišić, 2015; Cvetković et al., 2015), Mexico (Santos-Reyes et al., 2017), and Turkey and Lebanon (Baytiyeh \& Ocal, 2016). The research concluded that although students generally know about natural disasters, especially those with excellent grades, they need to improve education programs on natural disasters. Schools play a crucial role in educating students, parents, and teachers about natural disasters. Natural disaster programs have been included in schools in Japan for decades (Shaw et al., 2004). The two components of these programs are: to provide students with knowledge about natural disasters caused by earthquakes, their causes, and consequences, and to provide practical exercises on how to react in the event of an earthquake. It is necessary to follow the examples of developed countries to create thriving school programs on disasters.

Slovic (1992) analyzed the early results of psychometric studies, and one of the most exciting findings was that people wanted to answer questionnaires that lasted for several hours, giving hundreds of answers. Techniques of the psychometric approach proved to be good in detecting similarities and differences in respondents 'risk perceptions. There were differences in the understanding of the concept of risk between experts and non-experts, and 
there was a tendency for respondents to assess the existing risks as very high. Research has shown that risk tolerance is affected by the number of dead and injured, destroyed property as well as whether they consciously agreed to the risk or not (Slovic, 1987). People have more tolerance for consciously taken risks because they can benefit. Since Slovic, in his research (Slovic et al., 1985; 1887; 1992) omitted natural disasters, the research conducted by Henrich et al. (2018) aimed to expand psychometric analysis of risk characteristics, including earthquakes. They assessed risk assessments of 6 hazards: living in an earthquake-prone zone, smoking, consuming alcohol, flying an airplane, driving motor vehicles, and nuclear energy. All these dangers except earthquakes were on the list of dangers recognized by Slovic (1987). The second goal of the research was to determine which risk characteristics are related to risk tolerance. To this end, they used three risk tolerance measures: increased government funding, better regulation, and a willingness to pay taxes. The results showed that earthquake respondents wanted more government resources to be allocated to mitigate the consequences and reduce risks, while for other hazards, they felt better regulations were needed. Ohtomo, Kimura, \& Hirata (2020), researched the Kumamoto earthquake in 2016 to determine which factors, and to what extent, affect risk perception. The results showed that the perception of severity increases with experience with earthquakes, the perception of earthquakes depends on demographic factors and how much people are aware of the dangers of earthquakes, and the perception of uncertainty is formed by intuition. Relevant research was conducted in Bangladesh, Dhaka (Rahman, 2019) to examine the perception of seismic risks of Dhaka residents and determine the level of knowledge and preparedness of respondents depending on demographic factors: gender, age, level of education. The obtained results show that women perceive risks better and are better prepared than male respondents, younger ones have more knowledge than older ones and less educated people are less prepared than more educated people.

Since China is making its first earthquake insurance program, Tian et al. (2014) examined population risk perceptions in the regions covered by the program to provide data to help implement the program. They focused on the impact of previous experience with earthquakes and the respondents' type of house. Their results showed that those who suffered the terrible consequences of the earthquake have a higher risk perception and that securing a home is directly related to risk perception. Cvetković and Stanišić (2015), examined the relationship of demographic and social factors with knowledge and perception of natural disasters. They found that female respondents had a better knowledge of disasters while, on the other hand, gender had no impact when it came to disaster response. Students with better grades had more knowledge, so success in school is directly related to knowledge and procedures for dealing with natural disasters. Baytiyeh and Ocal, 2016, in a comparative study, examined earthquake risk perceptions of high school students in Lebanon and Turkey. They examined three factors: the perception of probability and consequence, the role of education, and fatalistic beliefs. Both groups showed a fondness for fatalistic beliefs. Although students in Turkey had more knowledge and awareness of disasters, education in both schools was not satisfactory.

Bronfman et al. (2016) found in their research conducted in Chile that citizens are most concerned about earthquakes, tsunamis, and forest fires, as well as that older person and the lower socio-economic class better perceive the risk of natural disasters and have more confidence in institutions. Han, Lu, Hörhager, \& Yan (2017) investigated the impact of trust in government on the level of preparedness of individuals in China and their perception of 
earthquake risk. All respondents survived the 2010 Yushu earthquake. The results showed that more trust in institutions leads to reduced risk perception. These findings can be explained by the fact that the government successfully fought the Yushu earthquake and thus increased the trust and support of the citizens. Armaş, Cretu, \& Ionescu (2017) examined the impact of psychological determinants: stress, locus of control, and self-efficacy on risk perception of human behavior in a potential earthquake in Bucharest. Socio-demographic characteristics make a difference, so women older than 50 and those with lower incomes are more susceptible to stress. In Serbia, Cvetković and Filipović (2019) researched earthquake risk perception and the connection with demographic, social, and psychological factors. Older, less educated widows/widowers, those who live in rented facilities, the unemployed, and those with incomes over 76,000 dinars have a high level of risk perception. In these categories, it is easier to influence the adoption of preventive measures.

Guided by the results of previous research, the paper presents a description of existing scientific knowledge on risk perception of natural disasters caused by earthquakes, which provided a basis for researching demographic factors that affect the perception of earthquake risk of citizens of the Serbian capital. However, the domestic literature has not sufficiently dealt with this, neither the perception of risk nor the factors that affect risk perception. The explicit goal of this research is to explain and interpret how demographic factors (gender, age, education) affect the perception of earthquake risk of the citizens of Belgrade.

\section{Materials and Methods}

The subject of the quantitative research is the examination of the influence of demographic factors on the perception of earthquake risk of the citizens of Belgrade, with a review of their preparedness. Given that Serbia is in a seismically active area, this research aims to determine how much the citizens of Belgrade are aware of the risk of earthquakes and how much they are prepared to react in the event of an earthquake. The relationship between gender, age, level of education, and facility ownership with risk perception was examined.

\subsection{Basic Characteristics of Respondents}

For the needs of this research, adult citizens of Belgrade were surveyed, and 235 answers were collected. Of the total number of respondents, there was a higher percentage of women $(54.9 \%)$ than men $(45.1 \%)$, while the most significant percentage $(33.2 \%)$ of respondents are in the age group 31-45 years, a slightly lower percentage are respondents from the group 18-30 years, while the lowest percentage $(11.1 \%)$ of respondents are from the age group of over 60 years. Respondents from the 46-60 age category make up $25.1 \%$ of the sample. Most respondents have completed high school $34.5 \%$, and the percentage of respondents who have completed postgraduate studies, master's and doctorate, is $30.2 \%$. Respondents with higher education are represented in the sample with $27.2 \%$. The highest percentage of respondents is married, $52.8 \%$, followed by single respondents, $20.0 \%$, and those in a relationship, $17.9 \%$. In contrast, the most significant percentage of respondents (50.2\%) live in a building owned by a family member, and the smallest number of respondents live in a rented building $(12.3 \%)$.

Table 1. Demographic and socio-economic characteristics of respondents. 


\begin{tabular}{|c|c|c|c|}
\hline Variable & Category & (f) & $\%$ \\
\hline \multirow{2}{*}{ Gender } & Male & 106 & 45.1 \\
\hline & Female & 129 & 54.9 \\
\hline \multirow{4}{*}{ Age } & $18-30$ & 72 & 30.6 \\
\hline & $31-45$ & 78 & 33.2 \\
\hline & $46-60$ & 59 & 25.1 \\
\hline & $60+$ & 26 & 11.1 \\
\hline \multirow{5}{*}{ Marital status } & Single & 47 & 20 \\
\hline & In a relationship & 46 & 19.6 \\
\hline & Married & 124 & 52.8 \\
\hline & Divorced or widow & 14 & 6 \\
\hline & Elementary & 2 & 0.9 \\
\hline \multirow{5}{*}{ Education } & Secondary Sch. (grade 8-9) & 81 & 34.5 \\
\hline & High school (grade 11-12) & 17 & 7.2 \\
\hline & Undergraduate & 64 & 27.2 \\
\hline & Master & 32 & 13.6 \\
\hline & Doctorate & 39 & 16.6 \\
\hline \multirow{3}{*}{ Ownership of the facility } & Personal property & 88 & 37.4 \\
\hline & Owned by a family member & 118 & 50.2 \\
\hline & Third-Party Ownership & 29 & 12.3 \\
\hline \multicolumn{2}{|c|}{ TOTAL } & 235 & 100 \\
\hline
\end{tabular}

\subsection{Questionnaire Design}

The survey questionnaire for this research was created based on questionnaires that have been used in previous research (Rego et al., 2018; Cvetković and Filipović, 2019; Cvetković et al., 2019; Buylova et al., 2020). The questions in the questionnaire were answered by circling the offered answer, by grading on a scale from 1 to 5 , or by writing a short answer. The questions were divided into three categories. The first part of the questionnaire was consisted of general questions about the demographic characteristics of the respondents, then the questions that would determine the level of awareness of the respondents about earthquakes, and finally, the questions for determining the respondents' preparedness. Before starting the survey, an analysis of domestic and foreign scientific research in which survey questionnaires were used was performed to adapt and create the questionnaire necessary for the needs of this research. Then a questionnaire was made, which was written in simple language, without the use of professional terms. A pilot survey was conducted on a section of the population to ensure that the questionnaire was clear and understandable to respondents.

\subsection{Analyses}

The data obtained in the survey were entered into the statistical program SPSS (Statistical package for social sciences). After that, a data check was performed in order to eliminate possible errors when entering the answer. The collected data were analyzed using descriptive statistics, and the frequency and percentage were determined. In the next step, the obtained data were crossed, i.e., the demographic characteristics of the respondents with the perception of risk, e.g., the connection between the level of education of the respondents and the preparedness for earthquakes. T-test and One-way ANOVA were used to examine the relationship between the variables and the earthquake risk perception. For the age 
variable, the relationship was analyzed with the Pearson correlation coefficient. All tests were two-tailed, with a significance level of $p<0.05$. Statistical analysis was performed using SPSS Statistic 17.0 (IBM SPSS Statistics, New York, United States).

\section{Results}

In order to determine the level of awareness about earthquakes, the first question that was asked was: "Do you think you live in a city that an earthquake could endanger?" The most significant percentage of respondents answered affirmatively to this question $(41.2 \%)$, but as many as $32.8 \%$ of respondents answered that they were not sure. The answers to the following question: "How do you assess the possibility of an earthquake in your city" show that almost half of the respondents $(48.1 \%)$ believe that an earthquake is partially possible. $29.4 \%$ of respondents believe that the possibility of an earthquake is unlikely, and the smallest number of respondents, $2.1 \%$, believe that an earthquake is absolutely possible.

Regarding assessing the period in which an earthquake will occur, the most significant percentage of respondents (41.3\%) believe that the earthquake will occur within 5 to 20 years. Approximately the same percentage of respondents have estimated that an earthquake will occur in a period of 5 years and a period of 20 to 50 years, $23 \%$ and $18.3 \%$. It is the same with the assessment for the next year and over 50 years, $7.2 \%$ and $10.2 \%$. In addition, the most significant percentage of respondents, $48.9 \%$, believe that their homes would be damaged in the event of an earthquake. The percentage of those who think their homes would not be damaged is $14.9 \% .38 .2 \%$ of respondents said they were not sure. In correlation with the previous question, respondents were asked to assess the level of damage they could suffer in the event of an earthquake. The most significant percentage of respondents (38.7\%) estimated that the level of damage would be mediocre, and $13.2 \%$ said that the damage would be negligible (Table 2).

Table 2. Attitudes related to earthquake risk perception.

\begin{tabular}{lccc}
\hline & Yes & No & Not sure \\
\hline Perception of the city's vulnerability to earthquakes & 41.2 & 26 & 32.8 \\
Earthquake vulnerability of households & 48.9 & 14.9 & 38.2 \\
Knowledge of household response procedures & 65.5 & 11.1 & 23.4 \\
Knowledge of outdoor response procedures & 56.6 & 15.7 & 27.7 \\
Owning a first aid kit & 57.9 & 33.2 & 8.9 \\
Possession of necessary supplies & 44.3 & 46.8 & 8.9 \\
Knowledge of number 112 & 49.8 & 50.2 & $/$ \\
Possession of insurance & 15.3 & 84.7 & $/$ \\
\hline
\end{tabular}

In order to check the level of preparedness, the respondents were first asked to assess their level of preparedness for earthquakes. The most significant number of respondents believe that they are partially prepared, $40.9 \%$. There is a large percentage of those respondents who think they are entirely unprepared, $19.1 \%$, while there is the lowest percentage of absolutely prepared respondents, only 9.4\%. After assessing personal preparedness, the respondents were supposed to assess the level of preparedness of the city of Belgrade. The results show that only $4.3 \%$ of respondents believe that Belgrade is prepared 
or absolutely prepared for earthquakes. Approximately two-thirds of respondents $(65.5 \%)$ believe that the city is unprepared or completely unprepared (Figure 1).

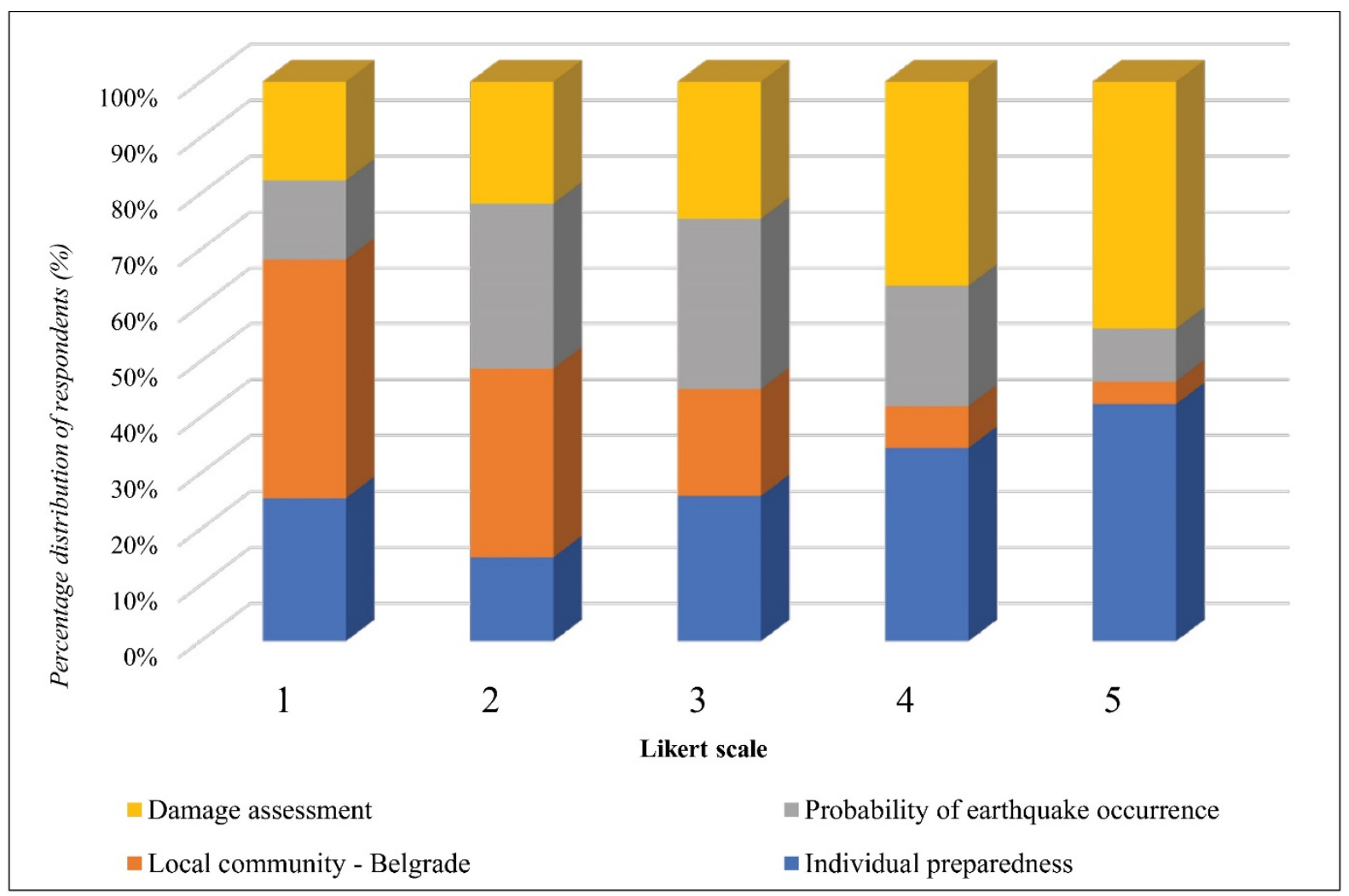

Figure 1. Attitudes on the Likert scale related to earthquake risk perception.

When asked: "Do you know how to behave during an earthquake if you are at home" (Table 15), 65.5\% of respondents answered that they know, while the percentage of respondents who do not know how to behave during an earthquake when they are at home is $11.1 \%$. The percentage of respondents who are unsure is $23.4 \%$. The next question was: "Do you know how to behave during an earthquake if you are outdoors." The percentage of respondents who answered yes to this question is $56.6 \%$, while those who do not know is $15.7 \%$. However, more than a quarter of respondents answered that they were not sure $(27.7 \%)$. The percentage of those who have a first aid kit is $57.9 \%$. In the follow-up questions for those who own a first aid kit, it was found that $65 \%$ of respondents keep first aid kits in an easily accessible place. However, only $37 \%$ of respondents have recently checked the contents of the kit. When asked if they have stocks of necessary groceries in their household. The percentage of respondents who do not have stocks is higher $(46.8 \%)$ than the respondents who have food stocks $(44.3 \%)$. Each European Union member state has an integrated protection and rescue system in emergencies - the system is "number 112 for emergency calls". This is one of the conditions for countries that want to become members of the EU (Lipovac \& Cvetkovic, 2015). The answers to the question of whether they know about the number 112 are divided. There is practically an equal number of respondents who know and those who do not know about the number 112. Finally, the respondents were asked whether they had insurance that covers the consequences of the earthquake. Of the total number of respondents, only $15.7 \%$ of respondents have earthquake insurance (Table 2 ). 
The T-test results show no statistically significant difference according to gender in relation to earthquake risk perception, perception of preparedness, and damage perception (Table 3).

Table 3. Independent samples t-test results between gender and the variables on earthquake risk perception.

\begin{tabular}{|c|c|c|c|c|c|c|}
\hline \multirow[b]{2}{*}{ Variable } & \multicolumn{6}{|c|}{ Gender } \\
\hline & $F$ & $\mathbf{t}$ & $\begin{array}{c}\text { Sig. } \\
\text { (2-Tailed) }\end{array}$ & $\mathrm{df}$ & $\begin{array}{c}\text { Male } \\
\text { X (SD) }\end{array}$ & $\begin{array}{l}\text { Female } \\
\text { X (SD) }\end{array}$ \\
\hline Earthquake risk perception & 3.51 & -.945 & .345 & 233 & $2.31(.970)$ & $2.44(.1 .11)$ \\
\hline Perception of preparedness & .645 & .126 & .900 & 233 & $2.08(.937)$ & $2.07(.894)$ \\
\hline Damage perception & 1.85 & .177 & .526 & 232 & $1.32(.726)$ & $1.23(.082)$ \\
\hline
\end{tabular}

Also, the correlation results between age and specific variables were investigated using Pearson's linear correlation coefficient. Preliminary analyses were performed to prove that the assumptions of normality, linearity, and homogeneity of variance were satisfied. There is a slightly positive correlation between age and earthquake risk perception, $r=.159 n=235$, $p$ $<.005$, perception increases with age (Table 4 ).

Table 4. Pearson correlation test results between age and variables regarding earthquake risk perception $(n=235)$.

\begin{tabular}{ccc}
\hline & & Age \\
\hline \multirow{2}{*}{ Earthquake risk perception } & Pearson correlation & $.159^{*}$ \\
& Sig. (2-tailed) & .015 \\
Preparedness & Pearson correlation & .031 \\
& Sig. (2-tailed) & .633 \\
\multirow{2}{*}{ Perception of damage } & Pearson correlation & .185 \\
& Sig. (2-tailed) & .075 \\
\hline
\end{tabular}

The results of the examination of the relationship between the level of education and the observed variables show no statistically significant correlation between the respondents' level of education and earthquake risk perception, repair, and perception of damage (Table $5)$.

Table 5. ANOVA test results between education and variables regarding earthquake risk perception $(n=235)$.

\begin{tabular}{|c|c|c|c|c|c|c|}
\hline & & Sum of Squares & $\mathrm{df}$ & $\begin{array}{l}\text { Mean } \\
\text { Square }\end{array}$ & $\mathrm{F}$ & Sig. \\
\hline \multirow{3}{*}{ Earthquake risk perception } & Between Groups & 3.346 & 5 & .669 & .865 & .505 \\
\hline & Within Groups & 177.182 & 229 & .774 & & \\
\hline & Total & 180.528 & 234 & & & \\
\hline
\end{tabular}




\begin{tabular}{ccccccc}
\hline \multirow{3}{*}{ Preparedness } & Between Groups & 3.906 & 5 & .781 & .938 & .457 \\
& Within Groups & 190.715 & 229 & .833 & & \\
& Total & 194.621 & 234 & & & \\
& Between Groups & .478 & 4 & .119 & .277 & .892 \\
\multirow{2}{*}{ Perception of damage } & Within Groups & 38.331 & 89 & .431 & & \\
& Total & 38.809 & 93 & & \\
\hline
\end{tabular}

\section{Discussion}

The primary goal of this research was to examine whether and to what extent demographic factors affect the perception of the risk of Belgrade citizens from natural disasters caused by earthquakes. Previous research conducted on this topic has shown that risk perception is influenced by a large number of factors, demographic, socio-economic, psychological (Armaş, 2006; Tian et al., 2014; García, 2017; Han et al., 2017; Shapira et al., 2018; Ao et al., 2020). In order to determine the level of awareness of the respondents, the question was asked whether they think that The earthquake could endanger Belgrade. Compared to the results of the research conducted by Cvetković and Filipović (2019), when $51.9 \%$ of respondents estimated that it was unbelievable to experience an earthquake, there is a significantly lower percentage of respondents who do not believe that an earthquake can occur. The recent earthquakes in the region, also felt in Serbia, could explain the increase in awareness about earthquakes. In Korea, after the earthquake that occurred in 2016, a survey was conducted to determine whether there was an increase in the respondents' level of awareness (Ha, 2018). In line with the previous research, it was concluded that the awareness was broadly higher and that this was especially noticeable among the respondents who participated in the recovery process after the earthquake.

The assessment results of the level of preparedness show that the largest percentage of respondents are partially prepared. Cvetković and associates (2019) came to the same results in examining the level of preparedness of the citizens of the Republic of Serbia. These results are consistent with a study conducted in Istanbul (Tekeli-Yeşil et al., 2010), which showed that people do not pay enough attention to the risk of earthquakes and take preventive measures because of the many risks in everyday life. When assessing the level of preparedness of the city of Belgrade, the results show that two-thirds of the respondents think that the city is unprepared for reaction, with a minimal percentage of respondents who assess that the city is prepared. These results were not in line with the research in Serbia from 2019 (Cvetković et al., 2019), when one-third of the respondents assessed their local self-government unprepared. For example, in a study conducted in China, the results show that respondents have tremendous confidence in the authorities and assess that they are prepared to react in the event of an earthquake (Han et al., 2017). This result is explained by the fact that the authorities successfully dealt with the Yushu earthquake, which increased public confidence.

A statistically significant association of gender with risk perception has been demonstrated in assessing the possibility of earthquakes and preparedness levels. Women showed a higher level of awareness, considering that a high percentage of men assessed the possibility of an earthquake as impossible. These results concur with the results obtained in a study conducted by Tian et al. (2014) in China, Fernandez et al. (2018) in Myanmar, and Bronfman et al. (2016) in Chile. On the other hand, research results show that men have a 
higher preparedness level than women, while, for example, a study conducted by Rahman (Rahman, 2019) in Dhaka showed that women are better prepared than male respondents.

When examining the influence of age on the perception of risk, it is noticed that almost half of the youngest respondents in the category of 18-30 years of age believe that the occurrence of earthquakes is impossible or unlikely. The youngest respondents probably think so because they have no experience with earthquakes. Respondents in a study conducted in Myanmar (Fernandez et al., 2018) cited a lack of experience as the reason for low-risk perception. Older respondents have a better perception of risk, which is in line with the research results conducted by Armaş (2006) in Bucharest and Ainuddin et al. (2014) in Pakistan. Respondents from the category of 31-45 years of age proved to be the least prepared.

The results of the Chi-square test in no case showed that the level of education impacts risk perception. The most significant difference is in assessing the damage that could be suffered in an earthquake, to which the respondents with secondary education in the most significant percentage answered that the damage would be serious or severe, almost $40 \%$ of the respondents. This can be explained by the fact that respondents with a higher level of education know that Serbia is not situated in a region characterized by devastating earthquakes (Cvetković and Filipović, 2019). However, respondents with higher education and postgraduate studies in a higher percentage stated that they are unprepared than the respondents with secondary education. This result is inconsistent with the results of research conducted in Bangladesh (Rahman, 2019), which showed that with more years of education, knowledge about earthquakes, response methods, and prevention measures increases.

When it comes to the impact of ownership of the facility, the results did not show a statistically significant association with risk perception; however, respondents living in a building owned by a family member, in the highest percentage believe that an earthquake is unlikely, while those living in personal property in the most significant percentage estimate that an earthquake is possible. A study conducted in Istanbul in 2011 (Tekeli-Yeşil, Dedeoğlu, Braun-Fahrlaender, \& Tanner, 2011) also did not prove a link between object ownership and risk perception. On the other hand, research in Korea (Moon, Hwang, \& Chung, 2019) showed that ownership of a facility has an impact on risk perception, given that respondents living in a facility that is personally owned take preventative measures and have insurance that covers the consequences of the earthquake, whereas the respondents who rent apartments do not. Regarding preparedness, the highest level of preparedness is expressed by respondents who live in a facility owned by a family member. On the other hand, a high percentage of those who are unprepared is also noticed.

The limitations of the conducted research are the coverage of a smaller territorial area and the population of the Republic of Serbia. The method of electronic surveying applied in this research has its drawbacks. They are reflected in the fact that there is no complete certainty regarding the credibility of its results. This implies the possibility for the same respondent to fill in the survey several times or provide incorrect answers. Also, one of the shortcomings is reflected in the fact that it is not possible to ask additional questions, or interpret the body language of the respondents, as is the case with the method of face-to-face examination. In addition, if the respondents do not understand the questions, it is not possible to provide additional clarifications and instructions in this method.

\section{Conclusions}


People's behavior at minimizing danger stems from one's perception of risk, probability of danger, efficiency, cost of personal precautions, and perception of potential consequences. Misperception of risk can lead to more significant consequences and losses. It is the perception of risk that shapes the behavior of individuals before and during danger. Therefore, it is justified and necessary to study the perception of risk and the factors that shape the perception of risk of individuals. When reviewing the current domestic and foreign literature, different results were observed, so that in some studies, the influence of some factors were confirmed, and in some other researches, the influence of other factors on the perception of risk. It is concluded that various factors can shape the perception of risk, and in the first place, those are demographic, socio-economic, and psychological factors. This research aimed to examine the perception of risk of the citizens of Belgrade from natural disasters caused by earthquakes and the impact of demographic factors on the perception of risk. Earthquakes happen very often, but in most cases, they are of low intensity. However, more destructive ones are possible, which leave significant consequences, and can cause great mortality. In 2010, an earthquake in Kraljevo in Serbia took two lives and left significant material consequences.

The results of the research show that women have a higher perception of risk. It has been proven that the youngest respondents from the age category of 18-30 have the lowest risk perception. The influence of education levels in no case showed a statistically significant correlation with risk perception. The association of gender with preparedness was confirmed; namely, men were better prepared than women, while no statistically significant association was proven at the respondents' age and level of education. Given the relatively high percentage of respondents who are unsure whether their city is at risk from the earthquake and the low levels of respondents' preparedness, it is clear that insufficient attention is paid to educating and informing citizens about natural disasters caused by earthquakes. It is necessary to follow the examples of developed countries that have incorporated disaster education into the education system, such as Japan (Shaw et al., 2004). The results obtained in this research can serve as guidelines and recommendations for the authorities and institutions, which can use them in their educational programs to improve the perception of the risk of natural disasters among citizens. By implementing educational and preventive activities, the consequences of natural disasters can be significantly reduced.

Earthquakes occur in a brief period. Practical efforts to adapt to and cope with earthquakes rely essentially on the extent to which the required knowledge, resources, and competencies are organized in advance and whether they are used quickly and efficiently if the need arises. Understanding how the public perceives earthquake risk is an essential first step in assessing a community's seismic vulnerability. This information can be crucial for professionals and policymakers to design mitigation strategies, prepare evacuation guidelines, and implement an effective disaster response. The results of this research provide insight into the attitudes and preparedness of the citizens of Belgrade, and given that risk perception plays a crucial role in taking preventive measures, it is imperative to conduct regular risk perception surveys. Few papers in the domestic literature deal with this topic, and given the seriousness of the consequences that earthquakes can cause, it is necessary to conduct regular research to monitor changes in the perception of risks that may occur in the future. Further research into the factors influencing risk perception could recommend effective measures that align with changes in the social environment. Future research should 
cover a more significant part of the territory of the Republic of Serbia and a more significant number of respondents.

\section{Acknowledgments}

The authors express their gratitude to the anonymous reviewers for their comments, and the Scientific-Professional Society for Disaster Risk Management (http://upravljanje-rizicima.com/) and International Institute for Disaster Research in Belgrade, Serbia for their scientific support.

Funding: This research was funded by the Scientific-Professional Society for Disaster Risk Management, Belgrade, Serbia (http://upravljanje-rizicima.com/) and International Institute for Disaster Research.

Conflicts of Interest: The authors declare no conflict of interest.

\section{References}

Ainuddin, S., Kumar Routray, J., \& Ainuddin, S. (2014). People's risk perception in earthquake-prone Quetta city of Baluchistan. International Journal of Disaster Risk Reduction, 7, 165-175.

Ao, Y., Huang, K., Wang, Y., Wang, Q., \& Martek, I. (2020). Influence of built environment and risk perception on seismic evacuation behavior: evidence from rural areas affected by Wenchuan earthquake. International journal of disaster risk reduction, 46, 101504.

Armaş, I. (2006). Earthquake risk perception in Bucharest, Romania. Risk Analysis, 26(5), 1223-1234.

Armaş, I., \& Avram, E. (2008). Patterns and trends in the perception of seismic risk. Case study: Bucharest Municipality/Romania. Natural Hazards, 44(1), 147-161.

Armaş, I., Cretu, R. Z., \& Ionescu, R. (2017). Self-efficacy, stress, and locus of control: The psychology of earthquake risk perception in Bucharest, Romania. International journal of disaster risk reduction, 22, 71-76.

Baytiyeh, H., \& Öcal, A. (2016). High school students' perceptions of earthquake disaster: A comparative study of Lebanon and Turkey. International Journal of Disaster Risk Reduction, 18, 56-63.

Becker, J. S., Paton, D., Johnston, D. M., \& Ronan, K. R. (2012). A model of household preparedness for earthquakes: how individuals make meaning of earthquake information and how this influences preparedness. Natural hazards, 64(1), 107-137.

Becker, J. S., Paton, D., Johnston, D. M., Ronan, K. R., \& McClure, J. (2017). The role of prior experience in informing and motivating earthquake preparedness. International journal of disaster risk reduction, 22, 179-193.

Bradley, D. T., McFarland, M., \& Clarke, M. (2016). The effectiveness of disaster risk communication: a systematic review of intervention studies. Effective Communication During Disasters, 81-120.

Bronfman, N. C., Cisternas, P. C., López-Vázquez, E., \& Cifuentes, L. A. (2016). Trust and risk perception of natural hazards: implications for risk preparedness in Chile. Natural Hazards, 81(1), 307-327. 
Buylova, A., Chen, C., Cramer, L. A., Wang, H., \& Cox, D. T. (2020). Household risk perceptions and evacuation intentions in earthquake and tsunami in a Cascadia Subduction Zone. International journal of disaster risk reduction, 44, 101442.

Cvetković, V. (2014). Zaštita kritične infrastructure od posledica prirodnih katastrofa. In Sedma međunarodna znastveno-stručna konferencija "Dani kriznog upravljanja". Hrvatska: Velika Gorica (Vol. 22, pp. 1281-1295).

Cvetković, V. (2016). Uticaj demografskih, socio-ekonomskih i psiholoških faktora na preduzimanje preventivnih mera. Kultura polisa, 13(32), 393-404.

Cvetković, V. (2017). Metodologija istraživanja katastrofa i rizika: teorije, koncepti i metode [Disaster and risk research methodology: Theories, concepts and methods]. Belgrade: Zadužbina Andrejević.

Cvetković, V. (2020). Upravljanje rizicima u vanrednim situacijama. Beograd: Naučno-stručno društvo za upravljanje rizicima u vanrednim situacijama.

Cvetković, V. M. i Filipović, M. (2019). Percepcija rizika od zemljotresa u Republici Srbiji-teorijsko-empirijska studija. Vojno delo, 71(2), 142-159.

Cvetković, V. M., \& Stanišić, J. (2015). Relationship between demographic and environmental factors and knowledge of secondary school students on natural disasters. Journal of the Geographical Institute Jovan Cvijic Sasa, 65(3), 323-340.

Cvetković, V. M., Filipović, M., Dragićević, S., \& Novković, I. (2018). The role of social networks in disaster risk reduction. In VIII International scientific conference Archibald Reiss days, Belgrade (pp. 311-321).

Cvetković, V. M., Ronan, K., Shaw, R., Filipović, M., Mano, R., Gačić, J., \& Jakovljević, V. (2019). Household earthquake preparedness in Serbia: A study of selected municipalities. Acta Geographica Slovenica-Geografski Zbornik, 59(2), 27-42.

Cvetković, V., Ivanov, A., \& Sadiyeh, A. (2015). Knowledge and perceptions of students of the Academy of criminalistic and police studies about natural disasters. Paper presented at the International scientific conference Archibald Reiss days, Belgrade, 3-4 March 2015.

Cvetković, V., Milojković, B. i Stojković, D. (2014). Analiza geoprostorne i vremenske distribucije zemljotresa kao prirodnih katastrofa. Vojno delo, 2(2014), 166-185.

Fernandez, G., Tun, A. M., Okazaki, K., Zaw, S. H., \& Kyaw, K. (2018). Factors influencing fire, earthquake, and cyclone risk perception in Yangon, Myanmar. International journal of disaster risk reduction, 28, 140-149.

Fothergill, A. (1996). Gender, risk, and disaster. International journal of mass emergencies and disasters, 14(1), 33-56.

García, F. E. (2017). Factores socio-demográficos, crecimiento y sintomatología postraumática en sobrevivientes del terremoto de Chile del 2010. Summa Psicológica UST, 14(1), 33-42.

Gasparini, P., Manfredi, G., \& Zschau, J. (2011). Earthquake early warning as a tool for improving society's resilience and crisis response. Soil Dynamics and Earthquake Engineering, 31(2), 267-270.

Goyal, N. (2019). Disaster Governance and Community Resilience: The Law and the Role of SDMAs. International Journal of Disaster Risk Management, 1(2), 61-75. 
Griffiths, M. (2015). Judging dread: A quantitative investigation of affect, psychometric dread and risk consequence. Retrieved from https://ro.ecu.edu.au/theses/1706

Han, Z., Lu, X., Hörhager, E. I., \& Yan, J. (2017). The effects of trust in government on earthquake survivors' risk perception and preparedness in China. Natural Hazards, 86(1), 437-452.

Heilbrun, K., Wolbransky, M., Shah, S., \& Kelly, R. (2010). Risk communication of terrorist acts, natural disasters, and criminal violence: Comparing the processes of understanding and responding. Behavioral Sciences $\mathcal{E}$ the Law, 28(6), 717-729.

Henrich, L., McClure, J., \& Crozier, M. (2015). Effects of risk framing on earthquake risk perception: Life-time frequencies enhance recognition of the risk. International journal of disaster risk reduction, 13, 145-150.

Henrich, L., McClure, J., \& Doyle, E. E. (2018). Perceptions of risk characteristics of earthquakes compared to other hazards and their impact on risk tolerance. Disasters, 42(4), 761-781.

Ho, M. C., Shaw, D., Lin, S., \& Chiu, Y. C. (2008). How do disaster characteristics influence risk perception?. Risk Analysis: An International Journal, 28(3), 635-643.

Jakovljević, V., Cvetković, V. I Gačić, J. (2015): Prirodne katastrofe i obrazovanje. Beograd: Univerzitet u Beogradu, Fakultet bezbednosti.

Jones, E. C., Faas, A. J., Murphy, A. D., Tobin, G. A., Whiteford, L. M., \& McCarty, C. (2013). Cross-cultural and site-based influences on demographic, well-being, and social network predictors of risk perception in hazard and disaster settings in Ecuador and Mexico. Human Nature, 24(1), 5-32.

Knuth, D., Kehl, D., Hulse, L., \& Schmidt, S. (2014). Risk perception, experience, and objective risk: A cross-national study with European emergency survivors. Risk analysis, 34(7), 1286-1298.

Kung, Y. W., \& Chen, S. H. (2012). Perception of earthquake risk in Taiwan: Effects of gender and past earthquake experience. Risk Analysis: An International Journal, 32(9), 1535-1546.

Lipovac, M. i Cvetković, V. M. (2015). Integrisani sistem zaštite i spasavanja u vanrednim situacijama-sistem 'Broj 112 za hitne pozive'. Evropsko zakonodavstvo, 14(54), 300-306.

Mano, R. M., Kirshcenbaum, A., \& Rapaport, C. (2019). Earthquake preparedness: A Social Media Fit perspective to accessing and disseminating earthquake information. International Journal of Disaster Risk Management, 1(2), 19-31.

Mizrak, S., Özdemir, A., \& Aslan, R. (2021). Adaptation of hurricane risk perception scale to earthquake risk perception and determining the factors affecting women's earthquake risk perception. Natural Hazards, 1-19.

Moon, J. W., Hwang, H., \& Chung, J. B. (2019). Factors affecting awareness of preparedness after moderate earthquakes: An analysis of the Pohang earthquake in Korea. Disaster Prevention and Management: An International Journal.

Ohtomo, S., Kimura, R., \& Hirata, N. (2020) The 2016 Kumamoto earthquakes' influence on residents' risk perception. In: 17th World Conference on Earthquake Engineering, 17WCEE Sendai, Japan.

Olawuni, P., Olowoporoku, O., \&amp; Daramola, O. (2020). Determinants of Residents'Participation in Disaster Risk Management in Lagos Metropolis Nigeria. International Journal of Disaster Risk Management, 2(2), 1-19. 
Plapp, T., \& Werner, U. (2006). Understanding risk perception from natural hazards: examples from Germany. In RISK21-coping with risks due to natural hazards in the 21st century (pp. 111-118). CRC Press.

Qing, C., Guo, S., Deng, X., \& Xu, D. (2021). Farmers' disaster preparedness and quality of life in earthquake-prone areas: The mediating role of risk perception. International Journal of Disaster Risk Reduction, 59, 102252.

Qureshi, M. I., Khan, S. U., Rana, I. A., Ali, B., \& ur Rahman, A. (2021). Determinants of people's seismic risk perception: A case study of Malakand, Pakistan. International Journal of Disaster Risk Reduction, 55, 102078.

Rahman, M. L. (2019). Risk perception and awareness of earthquake: the case of Dhaka. International journal of disaster resilience in the built environment.

Rego, I. E., Pereira, S. M., Morro, J., \& Pacheco, M. P. (2018). Perceptions of seismic and volcanic risk and preparedness at São Miguel Island (Azores, Portugal). International journal of disaster risk reduction, 31, 498-503.

Rico, G. (2019). School-Community Collaboration: Disaster Preparedness towards Building Resilient Communities. International Journal of Disaster Risk Management, 1(2), 45-61.

Santos-Reyes, J., Santos-Reyes, G., Gouzeva, T., \& Velazquez-Martinez, D. (2017). Schoolchildren's earthquake knowledge, preparedness, and risk perception of a seismic-prone region of Mexico. Human and Ecological Risk Assessment: An International Journal, 23(3), 494-507.

Shapira, S., Aharonson-Daniel, L., \& Bar-Dayan, Y. (2018). Anticipated behavioral response patterns to an earthquake: The role of personal and household characteristics, risk perception, previous experience and preparedness. International journal of disaster risk reduction, 31, 1-8.

Shaw, R., Kobayashi, K. S. H., \& Kobayashi, M. (2004). Linking experience, education, perception and earthquake preparedness. Disaster Prevention and Management: An International Journal.

Shrestha, S. R., Sliuzas, R., \& Kuffer, M. (2018). Open spaces and risk perception in post-earthquake Kathmandu city. Applied geography, 93, 81-91.

Sjöberg, L., Moen, B. E., \& Rundmo, T. (2004). Explaining risk perception. An evaluation of the psychometric paradigm in risk perception research, 10(2), 665-612.

Slovic, P. (1987). Perception of risk. Science, 236(4799), 280-285.

Slovic, P. (1992). Perception of risk: Reflections on the psychometric paradigm. Social Theories of Risk. Praeger. $117-152$.

Slovic, P., Fischhoff, B., \& Lichtenstein, S. (1985). Characterizing perceived risk. Perilous progress: Managing the hazards of technology, 91-125.

Sun, L., \& Xue, L. (2020). Does non-destructive earthquake experience affect risk perception and motivate preparedness?. Journal of Contingencies and Crisis Management, 28(2), 122-130.

Sund, B., Svensson, M., \& Andersson, H. (2017). Demographic determinants of incident experience and risk perception: do high-risk groups accurately perceive themselves as high-risk?. Journal of risk research, 20(1), 99-117.

Tekeli-Yeşil, S., Dedeoğlu, N., Braun-Fahrlaender, C., \& Tanner, M. (2011). Earthquake awareness and perception of risk among the residents of Istanbul. Natural hazards, 59(1), 427-446. 
Tekeli-Yeşil, S., Dedeoğlu, N., Tanner, M., Braun-Fahrlaender, C., \& Obrist, B. (2010). Individual preparedness and mitigation actions for a predicted earthquake in Istanbul. Disasters, 34(4), 910-930.

Tian, L., Yao, P., \& Jiang, S. J. (2014). Perception of earthquake risk: a study of the earthquake insurance pilot area in China. Natural hazards, 74(3), 1595-1611.

Xu, D., Zhuang, L., Deng, X., Qing, C., \& Yong, Z. (2020). Media exposure, disaster experience, and risk perception of rural households in earthquake-stricken areas: evidence from rural China. International journal of environmental research and public health, 17(9), 3246. 